\title{
Influences of Confucianism on Chinese Parents' Experience with Early Childhood Education
}

\author{
Shaohua Hong, Andrew Howes \\ The University of Manchester, Manchester, UK \\ Email: shaohuahong2011@gmail.com
}

Received 17 May 2014; revised 25 June 2014; accepted 10 July 2014

Copyright (C) 2014 by authors and Scientific Research Publishing Inc.

This work is licensed under the Creative Commons Attribution International License (CC BY). http://creativecommons.org/licenses/by/4.0/

(c) (7) Open Access

\begin{abstract}
Confucian concepts have long been seen as reflecting the main component of Chinese cultural civilization, which started in around 500 B.C. after Confucius passed away. There have been two significant Confucian movements. The earlier one appeared in the $12^{\text {th }}$ century, during the regime of the Song Dynasty, and the later one started in the $20^{\text {th }}$ century. These movements were both generally called new Confucian or Neo-Confucian. The rise of neo-Confucian thinking affects people from various aspects, including the way Chinese parents experience their child's early childhood education. This paper attempts to understand how Confucianism influences Chinese parents' experience with Early Childhood Education (ECE) by drawing upon a longitudinal study with a father from Urumqi, North-West of China, who sent his child to a local Confucian concept kindergarten, analysing tensions and contradictions within his experience. A series of in-depth interviews have been held with him over a period of a year, in particular relating to his selection of kindergarten and on-going perspectives. It has been revealed from this father's testimony that his experience is a process of going through a hybrid of cultural influences, which are Confucianism, Positivism and Western concepts. It has also been proved that his constant learning of Confucianism had an unavoidable influence on his experience. Moreover, his growth to personal maturity was also intertwined together with Confucianism, which therefore strengthened his commitment to Confucianism.
\end{abstract}

\section{Keywords}

Confucianism, Early Childhood Education, Chinese Parent

\section{Introduction}

Early Childhood Education (ECE) refers to the education that children obtain during the early stages of their 
childhood. This has long been an increasing area of interest among researchers, in relation to either children's own future development or their positive contributions to the development of society. Educators in China, one of the largest countries in the world in terms of population, like those in developed countries, have also begun to turn their attention to the "very early" education of children [1]. It has been found that factors such as government policy, market mechanism, people's attitudes etc., all play different but important roles in consideration of ECE and these factors have all attracted various researchers' attention to different extents [2].

Among those roles, parents, being their children's ECE decision makers [3], are increasingly considered to be important, and therefore they have been paid much more attention than ever before. Their beliefs, views, and values relating to their children's education as well as their choices of ECE can be found in a large body of studies. This study aims to understand how Chinese parents, particularly from Mainland China, experience their children's ECE. In investigating one father's experience with ECE, the influences from Confucianism, as a revived culture in recent China, are paid special attention.

\section{ECE Development in China}

Education in the early years has been considered to be important for children, family and society in China since ancient times [4]. With the development of Chinese society and the shifts of culture, the implementation of ECE has also been changed accordingly in many aspects. This contextual background will provide a general picture of ECE history in China particularly in relation to its changes of goals, contents, approach and its association with cultural shifts. Looking into the history of ECE in China will give an overview of the ECE movement in China and will provide an idea why and how ECE in China has reached its present form. It will also show a trend of changing interaction between the family and ECE provision.

\subsection{In China before 1840}

Confucianism, now considered to be "cultural heritage", has been embedded in Chinese life and has influenced people's ways of thinking and acting for thousands of years [5]. It has played a significant role in forming and maintaining Chinese culture and civilization. However, it has not remained static, but has gone through movements away from the traditional philosophy of Confucius [6]. It will not be possible to do this development justice here, so I will simply pick out some significant aspects to present the movements. Among them, the most noteworthy and dominant one was so-called Neo-Confucianism in the Tang-Ming dynasty, facing the challenges of Buddhism and Daoism in the $12^{\text {th }}$ Century. Neo-Confucianism added the basic element of spirituality, which provided great faith and power to strengthen the confidence of the people in their belief system. This involved teaching people to gain enlightenment in their own minds and not from outside sources. It helped mould Chinese culture into what it is today, which does not originate in Confucianism but in Neo-Confucianism [7]. In this study, the key elements of interest are those relating to the upbringing of children.

The goals and content of family education in ancient China were mainly guided and influenced by the doctrines in Confucianism and the core philosophy of goodness from Buddhism, which had always contributed to people's belief in getting along with others. The dominant and influential theorists were all advocators of Confucianism such as Yan Zhitui (531-595), Zhu Xi (1130-1200) and Wang Shouren (1472-1528) [8]. When nowadays people talk about Confucianism, they commonly link it with building morality and following disciplines of behaviour [9].

Under the influence of Confucianism, the family was considered to be the main educational place for young children, and family education directly influenced a child's development. There were two goals for family education: to become a person and to become a useful person. To become a person had two meanings, which basically implied to educate children to become an adult as early as possible. In order to achieve this, children were educated to get rid of childish characteristics such as being "active", "curious", "loving to play" "loving to eat" etc. the other meaning was to educate children to become right-minded persons, which was linked to what they were taught specifically. To become a useful person had different meanings in different classifications of family. It meant to have good educational attainment in a higher level family, while at a lower level it meant to master a skill so that they could alleviate the family financial burden [8]. The child was viewed as a little adult, so the purpose of education was to get rid of childish characteristics as early as possible. In the family, fathers were the main educators of children, while mothers, uncles and elder siblings also had the responsibility and authority to educate young children. They were expected, on the one hand to teach children knowledge, and on the other 
hand to set an example for children to follow.

The main constituents in educating a child, guided by neo-Confucianism, was filial piety to parents, frugality and integrity; getting along with others, which was mainly about how to do good things and treat people well rather than badly; disciplines of behaviour, which was mainly about daily behaviour such as how to stand and sit etc. and about how to respond to parents or elders; fundamental knowledge of reading, writing and calculating, among which reading was most addressed; hygiene habits, including forming habits to maintain personal hygiene and help to keep the family environment hygienic; and self-care ability such as how to eat, and how to speak properly according to gender [10].

\subsection{In Modern China (1840-1949)}

Since the late $19^{\text {th }}$ Century, China has undergone several significant stages of changes and development, facing different influences and causes, which in turn had delineated changing tasks and proposals for various changes of focus in ECE.

In the 1890 s and the beginning of the $20^{\text {th }}$ century, as one of the results of the military wars between China and Japan, ECE was mainly influenced by Japanese models, which to some extent were influenced by Western culture but modified to serve China's own national development. This may also be because of the similarity between the Chinese and Japanese cultures [11]. The educational authority at that time had already published "Regulations for Child Fostering School and Family Education" in 1904 and "Regulations for Implementing National Schools” in 1915. The main goals of ECE under those two Regulations were similar, which were to build children's healthy bodies, to unlock children's mental ability, to form good habits.

The first kindergarten was established in China in 1903, heavily modelled on the Japanese curriculum, including the content, methods, equipment and toys. Some traditional readings were still included in school teaching, such as the Book of Filial Piety, the Four Books etc. Even though ECE had started to be nationalized for children to accept school education, the main role of national ECE was defined as being to support family education [8]. Therefore, in the early $20^{\text {th }}$ century, the family was still playing the major role in providing education for young children, with support from schools.

In the 1920s, some educators like Kang Youwei, Hui Daiying, Song Hua, Yang Xiaochun etc. believed that parents lacked the ability to educate children and pointed out that educating a child was a difficult task, which could not be implemented by parents. They therefore advocated the necessity of having certain institutions to provide proper and adequate education for children [12].

Meanwhile, Western science was introduced to China and aroused advocates of “Total Westernization” [5]. Western educators such as Frobel, Montessori and Dewey with their progressive theories had been brought into China and aroused great interest in child development. The philosophy and practice emphasized in the kindergarten curriculum was child-centred. Advocates claimed that the curriculum should come directly from the children's lives and experiences and this included children's natural activities. Teaching at this stage was supposed to be based on children's psychological development. Heqin Chen (1925), who was highly influenced by Dewey's positivism, pointed out that nature and society as a whole should be the core of a curriculum. Chen also proposed implementing "unit pedagogy”, published a book about “Test of Intelligence”, and adopted play as the method of education.

In 1932, the Educational Authority published the first “Standard of Kindergarten Curriculum”, which covered goals, contents and approaches. The major movement in this "Standard” was, it added, "to pursue children's natural happiness" towards the goals, even though to support the family to educate children and improve family education remained important [8].

It can be seen that the family were still playing the major role in educating children; however, the growing role of kindergartens was obvious. Doctrines of Confucianism, educational approaches from Japan and later Western theories had intertwined influences on the development of ECE as well as the views of children and parents in China at this historical stage.

\subsection{In Recent Modern China (1949-1978)}

Since the founding of the People's Republic of China in 1949, central government has paid a great deal of attention to ECE. This was seen to be due to the advocates of Maoism and the adopting of Marxism-Leninism, which gave the Chinese a desperate desire to get rid of poverty and gain freedom [13]. Confucianism was viewed as an 
old tradition and widely rejected at state level.

In the 1950s, the change of political era and the emphasis on social-economic development placed two tasks on early childhood education after liberation: to educate a new generation and to free women from sole responsibility for childcare [14]. In 1952, the central Education Authority published a "Guideline for Kindergarten Teaching” which was considered to be a sign for establishing the Chinese ECE central system [8]. To support parents to provide family education was removed from the goals and to cultivate children to have qualities related to being new national citizens, such as honesty, bravery, unity, kindness, discipline, politeness etc. and to foster children's creativity were added.

The reform in ECE was supported by psychological and educational theory developed in the Soviet Union. The child-centered approach was abandoned and teacher-centered theories and practices were adopted. A teacher-centered pedagogy was emphasized in the curriculum and teachers were advised to instruct children in purposeful and planned activities [15]. Previous focuses on cultivating individual children's behaviours were replaced by implementing the recitation and memorization of poems and quotations from Chairman Mao with the goal to develop a new generation who would "love the workers, peasants and soldiers"; "care for each other, love and help each other"; "love Chairman Mao, love labour, and "serve the people”. It was therefore seen by some Western visitors that the Chinese had a profound faith that the proper educational procedures were able to produce desired attitudes, values and emotions in children [16].

In 1966, ECE encountered a serious setback during the Cultural Revolution, which lasted until 1976. Many schools, including kindergartens, were forced to shut down during this ten years chaos [1], all the previous theories and practices were neglected and the existing, effective administrative system was abandoned. Children at preschool were considered citizens of China, having the same responsibilities as other groups who were over the age of seven and adults, so that the values and attitudes taught in preschool were designed primarily to focus on children's thoughts on political tenets [17].

During these three decades, ECE encountered growth and then setbacks due to political reasons, however, the movement towards a formal ECE system had appeared and the emphasis on providing education for children had started to shift from families to kindergartens. Meanwhile, the teacher-centred teaching curriculum had shown a tendency towards formal schooling in Kindergarten learning.

\subsection{In Present Day China (1978-Now)}

Following the Cultural Revolution until the 1980s, the national focus moved from political crisis to economic development and building up modernization. The national emphasis accordingly moved from the role of individual leaders to realisation of modernization so that the goal of preschool education at that time was to "work for the achievement of the Four Modernizations as early as possible”. There was a national campaign in 1979; called "We Love Science" with the purpose of making every boy and girl realize the importance of science in achieving four modernizations. Meanwhile, children were expected to set high goals for themselves and study hard for the motherland, so that kindergartens attempted to foster children's five loves-love of motherland, the people, science, physical labour and collective property. Children were also encouraged to "learn to love all, help each other and care for each other”. This reflected how values and attitudes in education had been moved from a political emphasis to "collectivism ideological and moral teaching” [23].

Later, when China set up its Economic Reform and Open-up Policy in the late 1970s until mid-1990, there had been great effects on every part of society including preschools. Along with the open-door policy, Western educational theories such as those of Dewey, Montessori, Bronfenbrenner, and Bruner, as well as those of Piaget and Vygotsky, had been either newly introduced or reintroduced to China [18].

“Kindergarten Work Regulations and Procedures", issued by the National Education Committee (the former Ministry of Education) in 1989, was thought to be the most influential measure of Chinese ECE curriculum reform. Central government provided guidance for educating children, who aimed at raising a generation having adequate health; appropriate morality; and enhanced intelligence. It emphasized five aspects: child-initiated activity; individual differences; the importance of play; an integrated curriculum and the process of activities. After that, the Chinese government issued several important announcements in order to improve the overall quality of ECE, such as "Guidance for Kindergarten Education” in 2001, which stated specific requirements and content in different domains [19].

To date, the current national purpose stated in the modified version of “Guidance for Kindergarten Education” 
in 2012 is to develop children's physical, intellectual, moral and aesthetic growth and provide a fundamental base to enable children to be well-prepared for future study and entire life development [20]. It covers five main areas in children's learning and development: Health (psychosocial and physical development; physical activities; habits and abilities of daily living); Language (listening and speaking; reading and writing), Social sense (interpersonal activity and adjustment to society); Science (natural sense and mathematics); Art (feeling and appreciating; performing and creating). The key principles in ECE guidance point out that ECE should follow children's regular pattern of learning; focus on children's psychosocial and physical intergraded development; and respect children's individual differences.

Seen from the above description, the time after China set up economic reforms can be viewed as a period bringing obvious change in ECE system orientation, which moved from collectivist ideological and moral teaching to children's integrated and individual development. The emphasis of educational areas in the Guidance for Kindergarten Education in 2012, modified from the Kindergarten Work Regulation and Procedure in 1989, can be seen as a development throughout the journey of cultural influences. Morality is an ideology from Confucianism, (and later Neo-Confucianism), but the emphasis of its meaning has been shifted from filial piety, frugality and integrity to interpersonal activity and adjustment to society, which reflects what Western ideas addressed. Physical covers psychological development, which is also Western concepts advocate, but it also keeps habit building which is rooted in Confucianism. The Western concept of science has been an emphasis in education since 1979, even though it serves a very specific national development purpose. The influence remains and it makes intellectual development, in particular about natural sense and mathematics, an important area in current ECE.

These documents appear to be formed from these areas, but the question remains how this looks from a parental perspective, or what it looks like in practice; how this is enacted in an actual school, or what this means to key stakeholders whose interests rely on this practice might be different. We therefore decided to do a case study with one parents' choice and experience, with priority for his son's education, to focus on the parental perspective in this paper.

\section{Methodology}

Essentially, case study is employed as an approach to investigate parents' experience since it is considered to be suitable to collect data about actual human events and behaviours [21]. In understanding the case itself, a narrative approach is adopted, as human experiences can be better understood as stories that include an event or several events in a chronological order and an effort to make something out of those events [22]. Parents' choice of provision are very likely to be an on-going decision as they are making sense of what happens to them and they are carrying on working on their choice, so that it should be an unfolding story. Based on this suspicion, the research is eventually designed to be longitudinal, involving three interviews about their choice and experiences with their child's ECE in one year.

The main challenges and difficulties in doing such a longitudinal research included how to gain access to suitable participants and how to keep them interested in engaging with the research throughout a year. To solve the former consideration, focus groups were initially conducted to ensure participants' understanding of the nature of the research and willingness to engage. The latter difficulty was carefully considered in deciding how to position the interviewer in relation to the participants. We thought it would be important to position the interviewer as somebody who was neither an expert knowing everything, nor an uninformed person who was just interested, but somebody understanding, who was also willing to listen to them. To achieve this, we carefully designed interviews to be both narrative and semi-structured, since narrative allowed parents more space and comfort to tell their stories [23] and semi-structured would convey to participants a sense of the interviewer's knowledge [24].

Apart from the interview design, we also made great efforts to show respect to participants. For example, as there were three interview sessions conducted with the parents, the time was communicated with them in advance and arranged at their convenience. Also, the topic covers parents' views, perceptions, and experience, which might cause them to be sad during the interview. In that case, we were prepared to be ready to take a break and ask their willingness to continue or rearrange. To ensure that all participants had a clear understanding of what the research was about, research information, such as the purpose of the study, voluntary participation, withdrawal process, anonymity in the report, data protection and destruction was communicated and explained. 
Permission for note taking and tape-recording was asked for. Once an agreement was made, signing of the consent form was confirmed. Nevertheless, before gaining permission from parents, initial contact and friendly communication was made, since participants would not open their hearts to talk only by signing the form [25]. The key point of doing all these was with the intention of making parents feel comfortable, and using a tape recorder during interviews was also to help the researcher to concentrate more on communicating with participants rather than using it as a substitute for "listening" closely throughout the course of any interview [26].

With the thoughtful research design, considering both the need of doing this type of research and suitably positioning interviewers in relation to parents, and the constant efforts, emphasizing parents' feeling of being comfortable in order to increase the level of their openness, rich data was collected. Thematic analysis was then undertaken to see what was important from the data, but since we had already decided the importance of narrative by this point, using those themes within narratives became the methodology. These two methods were considered to be a suitable match to use together to analyse individual cases [27]. In practice, the flow of each case study report remained the same, consisting of an introduction to the case; chronological order of description; summary of parents' narratives with a focus on their tensions and contradictions. Adopting this approach could not only keep the origin of the story, but also provide an opportunity to see the changes, as well as some possible reasons underlined. One case was chosen to be particularly presented and analysed for this paper.

\section{Findings: Commitment to Confucianism}

Yuanshan is a businessman, who is originally from Sichuan Province and has been in Xinjiang Autonomous Region for about 15 years. His son was born in November 2008 and then was sent to a Confucian kindergarten nearby at the age of 2 years and 9 months. By the time Yuanshan was at the first interview in December 2011, the child had been in kindergarten for 3 months. And then by the third interview in August 2012, the child was 3 years and 10 months old and had been in kindergarten for almost a year.

When selecting a kindergarten, Yuanshan and his family did not consider much. All they wanted was a public one nearby. When his mother noticed this KG nearby, he and his wife went to have a visit and formed a good initial impression. They did not try to choose a Confucian type of KG on purpose and he considered the choice a really simple process, as he said:

“...we selected the KG very easily at that time. It was only because my mum said it was quite near. It was really simple...” (SXY_I1_Q1:01)

“...We did not know they teach Confucianism at that time... What we preferred was only somewhere nearby...” (SXY_I1_Q1:02)

After the child had been in the KG for three months, Yuanshan realized that Chinese children nowadays lacked rules and norms, which were the "root" of Chinese, so he did not think that child's characters should be considered at this stage. He believed:

"...child should be taught to behave, to implant some rules, norms, and ideas about what are right into him so that these would be embedded into his whole life, being his 'roots'...”(SXY_I1_Q2:02)

He further claimed that it was important to form healthy living habits as good habits would benefit the child the whole life, making him feel relaxed and living in a relaxed mood. He said that

“... People's life can be planned and predicted and if people clearly planned their life, they could live clearly...” (SXY_I1_Q2:02)

He expected that his son could live happily and he believed there should be that kind of happy life. He hoped:

"...I wish that my son could live happily. I believe that kind of happiness is not necessary and not possible to be gained by using money. It is people's own rich and powerful mind...” (SXY_I1_Q4:10)

It seems that Yuanshan has expectations of his child, in relation to on the one hand following rules, building healthy living habits, on the other hand, being happy throughout his life. This raises a question of whether there is a link between following rules and being happy, which lookvery contradictory to each other.

He further expressed his thanks to his parents that he had never thought about it before:

“...I feel really grateful to my parents. They have been playing their roles so that I have been regulated and developed to what I look like today. I feel really thankful...” (SXY_I1_Q6:23)

It can be interpreted that because he felt he was regulated with certain rules at an early age and he saw the benefits in himself, he would like to educate his child in the same or at least similar way.

After eight months of his child being in the kindergarten, Yuanshan felt happy, as his child had shown very 
good memorizing ability.

"...He has very good ability to memorize that he can recite whole $<$ Dizigui $>$ and $<$ Book of Filial Piety $>$ from chapter one to chapter nine. He has only been learning these for almost eight months...” (SXY_I2_Q1:02)

He also noticed that the child showed great change in daily performance, in particular had been very polite, for example firstly his son said goodbye to teachers and classmates every day without being told by anyone and secondly he was told to greet people before entering kindergarten, but now he bent to say hello to teachers and other older people proactively.

Based on his child's performance, Yuanshan thought this KG was an absolutely right choice for his child. He was very satisfied with both playing facilities and teacher's attitude. He said:

"...I have no detailed requirements for eating in school. The child has been almost 18 kilogram, much higher than the standard weight $15 \mathrm{~kg}$. All other health indicators of him are above the average, so my wife and I did not have any higher requirement to school for child's eating. In reality, we do not care this much..." (SXY_I2_Q2:05)

But, in the meantime, he also found that the boy was too active and hard to quiet down. The child could play anything at home. For example, when his toys were taken over, he could even play stones. Yuanshan said:

"...He is too active and hard to quiet down. Once, I thought he might over take sugar as I searched on internet about this, it only said overtaking sugar may cause being too active...” (SXY_I2_Q3:08)

"...I asked teachers about his over active, teacher said it is normal and suggest trying to make him to quieten down and concentrate when doing things...” (SXY_I2_Q3:09)

So, he and his wife tried to guide the boy to concentrate on one thing each time, such as when reading, the boy would be trained to focus on reading only, not to take it as a task and think about playing. It is interesting to see that he is committed to the philosophy of Confucianism in terms of learning rules, but when there is perceived behavioural problem, he linked it to the scientific measuring idea in positivism.

In summary, from Yuanshan's narrative, there are several dominant themes, such as his strong personal philosophy about the innate blank canvas of a child; perceptions on the important role of parents; expectations of the child being "happy" and a "real person" in the future; belief about the rules and disciplines in children's education. By understanding and examining the themes, a tension was found: his holistic philosophy of Confucianism about educating a child by rules encountered the discursive philosophy of positivism about indicating a child's health by measuring numbers. A contradiction was also found in his expectations of his child: that he expected his child on the one hand to be happy, but on the other hand, he confirmed the necessity of learning rules. These emerging tensions and contradictions are summarized and explained.

\subsection{Tension-Understanding of Child: Holistic Philosophy of Confucianism VS Discursive Philosophy of Positivism}

Seen from Yuanshan's narrative, he had developed some understanding of his child over the year. His description of his child's change has been shown to follow his consistent personal understanding of Confucianism. For example, he was satisfied with his child's change because he showed good memorization ability by reciting Dizigui and Book of Filial Piety; he thought it was incredibly good that his child at this age was able to care about others' feelings; he felt that his child was very polite as he proactively bent to greet the older person. Interestingly, among all the evaluations of his child's behaviour and character from Confucius' concepts, he showed a discursive philosophy of positivism when he realized the boy was too active and hard to quieten down. He was not sure about the reason for the child's being too active but assumed he might be eating too much sugar. However, after he sought advice from the school teachers, he did not continue to look for whether his child had really eaten too much sugar but decided to train his child to quieten down by requiring him to concentrate on doing one thing at one time (he believed this was from one of the Confucian concepts).

His developed understanding of Confucianism could also be seen when he mentioned that he felt there was no lack of learning for the child, and that there would be no lack of any part of knowledge within Chinese traditional cultural learning, so that he believed this would not restrain the child's personality development to any extent (SXY_I2_Q1:02). In addition, it could also be seen in his high trust in the KG teaching, as he said in his narrative that it was not necessary to worry about anything, because in many respects, teachers had already considered the issue before the parents $\left(S X Y \_I 2 \_Q 1: 07\right)$ and he also mentioned that he did not think there was any problem about learning in this place (SXY_I2_Q1:01). 
His commitment to Confucianism and trust in the kindergarten could further explain why there appeared another tension from his discursive philosophy of positivism in his description, even though he did not realize it, which was how he perceived his child's health and character. One was about the child's weight etc. he said the child had been almost 18 kilograms, much higher than the standard weight of $15 \mathrm{~kg}$. All his other health indicators were shown above the average, so his wife and he did not have any higher requirement to the school for the child's eating (SXY_I2_Q2:05).

\subsection{Contradiction: Expectation of Child Development-To Be Happy and a Real Person, To Learn Rules}

Yuanshan expected the child to form healthy living habits and he believed habits formed in the early years would benefit the child's whole life. The habits should include how to eat; how to sit, how to walk; how to get along with others etc. These were well stated in Dizigui, being used in the class and to regulate children in the KG. Learning in the KG fulfilled his expectations of child outcome and the child's change after being in the KG further supported his satisfaction with the KG. Yuanshan believed that education at this stage formed a fundamental base for the future. It would regulate children's behaviour and form their habits. Even though they might not understand what they had been learning, it would benefit them when they grew up. He therefore kept asserting the importance of making children understand and follow rules and disciplines. He believed children should be taught how to behave and rules, norms and ideas should be implanted in them. These would be embedded into their lives. Meanwhile, he expressed several times his expectation of his child to live happily in the future. He believed there should be that kind of happy life, which was irrelevant to money, and he believed it should be achievable. In addition to being happy, he also stated that he wished his child could become a "real person", which would not be equal to "successful”. This raises the question whether learning and being regulated through rules and disciplines means being happy to the child.

His commitment to learning rules might be because he viewed the contemporary problems of educating children, as he said that it had been difficult to educate children nowadays, because parents did not have that kind of "roots" in them. They therefore did not know what would be good for their children and what would not (SXY_I1_Q6:26). It might also come from his view of childhood: that he believed children had no ability to distinguish good from bad; therefore, parents should have to choose for them (SXY_I2_Q4:06). In addition, his growing understanding of and commitment to Confucianism might have also contributed to his beliefs about the importance of rules and disciplines for a child. From his viewpoint, it seems learning rules will enable children to achieve happiness. What parents should do is to adopt those rules and implement them for their children. This reveals that there is very strong tradition in which people can always take shelter because it is safe. It is a place of safety and people do not need to be worried. He brings out the desirability of not having to think and worry about things, and being confident in a received, tried and tested tradition. He believed that “...We thought there were gaps between children and parents, but actually there were not. If thought is coherent, there will not be any gaps. It is just like we are still learning Confucianism after thousands of years. (SXY_I1_Q6:25)”.

\section{Discussion: Confucianism, Positivism and Western Ideas}

Seen from Yuanshan's story, he was sometimes aware of tension in his decisions and activities concerning their children, and these caused him considerable anxiety. In contrast with the tension, his activities and decisions sometimes contained contradictions of which he was unaware, but which also affected the way in which he organized his child's early years.

\subsection{Confucianism VS Positivism}

Even though Yuanshan demonstrated his commitment to Confucianism throughout his whole experience, there was one mini story showing his uncertainty about his child's being over naughty. He was confused for a moment about whether his child had consumed too much sugar. Also in the other instance when he mentioned the meals provided at the KG, he used exact numbers to prove his satisfaction. These instances are not surprising: people who grew up in the 1970s tend to incautiously use such a positivist approach to justify issues, as it has been working on people's lives in China since the late 1970s when the Cultural Revolution finished. At that time, the national emphasis accordingly moved from the role of individual leaders to realisation of modernization so that 
the goal of preschool education at that time was to "work for the achievement of the Four Modernizations as early as possible". There was a national campaign in 1979, called "We Love Science" which is rooted in the ideology of positivism and greatly influenced people in that generation [23].

It appears that Confucianism was influencing him so that all his expectations, beliefs, selection of learning activities and all aspects in relation to his child's ECE proactively followed this specific philosophy, where disciplines and rules are emphasized. However, since he grew up in the period when the philosophy of positivism was adopted widely throughout the country, it had some unanticipated influences on him, which resulted in his tension in perceiving his child's behavioural problem.

\subsection{Confucianism VS Western Ideas}

In terms of child development, Yuanshan showed inconsistent expectations in his narrative. The inconsistency was mainly between being happy as a general expectation and learning rules as a different specific expectation. It initially rose as question whether this specific expectation would lead to happiness. This appeared to be a contradiction, as if he placed learning rules as an expectation, then he would be guided by this, rather than by the philosophy of being happy to direct his child's life. It would be a valid question whether it could bring happiness to the child in the end or not. This then raised a second question of where the idea of being happy came from.

When China set up its Economic Reform and Open-up Policy in the late 1970s until mid-1990, there had been great effects on every part of society including preschools. The Government announced several significant policies [28], among them "Kindergarten Work Regulations and Procedures" in 1989 and a modified version about "Guidance for Kindergarten Education" in 2012. In these, even though specific areas of physical, intellectual, moral and aesthetic growth are addressed, the core address is child-centred and respects children's individual differences. These ideas originally came to China from Western countries, since Western educational theories such as those of Dewey, Montessori, Bronfenbrenner, and Bruner, as well as those of Piaget and Vygotsky, had been either newly introduced or reintroduced to China along with the open-door policy in 1978 [29].

When the father talked about his expectations about his happiness, from one aspect, it can be interpreted that he was trying to express his respect for the child's natural development. Being happy can be seen as a commonly used term in Chinese society nowadays in replace of respect or child-centredness. From the other aspect, it can be interpreted that the father was actively engaging in thinking what happiness means to him and to his child, and the philosophy of Confucianism is reflected in his expressions that “... happiness is people's own rich and powerful mind...”. It is hard to say which particular philosophy influenced the parent to have this idea, but what is obvious is that the father is not simply taking any philosophy in educating his child. He is actually an active thinker about his child's ECE as well as his child's life.

\subsection{Personal Learning Confucianism VS Personal Upbringing History}

In the meantime of finding the different cultural influences on his perspectives on ECE, his personal upbringing had also played some role in his perceptions about what to learn in the early years. When he explained why they decided to choose a certain type of learning, they referred back to their own learning in the early years. He viewed himself as having been brought up in a Confucian family environment, which made him different from many others. He believed children's problems were because parents did not know clearly what should be right and what should be wrong. These could only be solved through learning Confucianism. It seems his upbringing helped him recognize the importance of Confucianism in people's education and then his constant learning strengthened his growing commitment to a re-acknowledgement of its importance.

\section{Conclusion}

This study looked into how Confucianism might influence parents' experience with their child's early childhood education by analysing a father's narrative. The significance of the paper which in general speaking showed that there was significant effect of values learned on Confucianism as shared by the parent in his child. It was found that Confucianism had positively influenced his views on education and life, while other ideologies such as Positivism and some Western concepts had also been playing a role in shaping his perspectives on children, education and life. Therefore, it appears that along with the social changes parents are facing, they are also experiencing influences from the hybridisation of cultures, which are either embedded in their personal upbringing 
or encountered in their educational and life experiences and then influence their views on children and education. Apart from influences from his perceived Confucianism and unperceived other philosophies, his own upbringing also contributed to shaping his overall experience. Despite these influential factors, the parent is not perceived as a passive receiver but an active thinker in relation to his child's ECE and life development.

\section{References}

[1] Zhu, J. and Zhang, J. (2010) Contemporary Trends and Developments in Early Childhood Education in China. Early Years, 28, 173-182. http://dx.doi.org/10.1080/09575140802163584

[2] Corter, C., Janmohammed, Z., et al. (2006). Selected Issues Concerning Early Childhood Care and Education in China. United Nations Educational, Scientific and Cultural Organization Paper commissioned for the EFA Global Monitoring Report 2007.

[3] Rose, K.K. and Elicker, J. (2008) Parental Decision Making about Child Care. Journal of Family Issue, 29, $1161-1185$. http://dx.doi.org/10.1177/0192513X07312103

[4] Ebbeck, M. and Gao W. (1996) The Importance of Pre-School Education in The People’s Republic of China. Journal of Early Years Education, 4, 27-34. http://dx.doi.org/10.1080/0966976960040102

[5] Seong, H.C. (2003) Modern Chinese COnfucianism: The Contemporary Neo-Confucian Movement and Its Cultural Significance. Social Compass, 50, 481-191. http://dx.doi.org/10.1177/0037768603504007

[6] Chan, W.-T. (1967) Neo-Confucianism: New Ideas in Old Terminology. Philosophy East and West, 17, 15-35. http://dx.doi.org/10.2307/1397042

[7] Tucker, M.E. (1991) The Relevance of Chinese Neo-Confucianism for the Reverence of Nature. Environmental History Review, 15, 55-69. http://dx.doi.org/10.2307/3984970

[8] Hu, J. and Zhou, C. (2011). International and Chinese Early Childhood Education History. Higher Education Publisher, Beijing.

[9] Yost, T.J. (2002) A Historical Setting for the Forming of Neo-Confucianism in Classical China. Studia Antiqua, 2, 113-123.

[10] Kinney, A.B. (2004). Representation of Childhood and Youth in Early CHINA. Stanford University Press, California.

[11] Mok, K.-H. (1997) Retreat of the State: Marketization of Education in the Pearl River Delta. Comparative Education Review, 41, 260-276. http://dx.doi.org/10.1086/447446

[12] Bai, L. (2010) Human Capital or Humane Talent? Rethinking the Nature of Education in China from a Comparative Historical Perspective. Frontiers of Education in China, 5, 104-129. http://dx.doi.org/10.1007/s11516-010-0008-z

[13] Liu, B. (1993) Civilization Grafting: No Culture Is an Island. Foreign Affairs, 72, 19-21. http://dx.doi.org/10.2307/20045711

[14] Nyland, B., Nyland, C., et al. (2009) Early Childhood Education and Care in Urban China: The Importance of Parental Choice. Early Child Development and Care, 179, 517-528. http://dx.doi.org/10.2307/20045711

[15] Spodek, B. (1989) Chinese Kindergarten Education and Its Reform. Early Childhood Research Quarterly, 4, 31-50. http://dx.doi.org/10.1016/S0885-2006(89)90051-3

[16] Mcloughlin, C.S., Pang, L., et al. (1997) The Past, Present and Future of Chinese Early Childhood Education. School Psychology International, 18, 275-288. http://dx.doi.org/10.1177/0143034397183007

[17] Sidel, R. (1982) Early Childhood Education in China: The Impact of Political Change. Comparative Education Review, 26, 78-87. http://dx.doi.org/10.1086/446264

[18] Wu, X. (2011) The Power of Positional Competition and Market Mechanism: An Empirical Study of Parental Choice of Junior Middle School in Nanning, P.R. China.

[19] Wang, J.H. and Mao, S.Y. (1996) Culture and the Kindergarten Curriculum in the People's Republic of China. Early Child Development and Care, 123, 143-156. http://dx.doi.org/10.1080/0300443961230110

[20] Gu, L. (2006) Chinese Early Childhood Education in Transition. Wingspan: The Pedamorphosis Communiqué, 16, 3041.

[21] Yin, R.K. (2009) Case Study Research: Design and Methods. Sage Publications, Inc., California.

[22] Sandelowski, M. (1991) Telling Stories: Narrative Approaches in Qualitative Research. Image: The Journal of Nursing Scholarship, 23, 161-166. http://dx.doi.org/10.1111/j.1547-5069.1991.tb00662.x

[23] Clandinin, D.J. and Connelly, F.M. (2000) Narrtive Inquiry: Experience and Story in Qualitative Research. John Wiley \& Sons, San Francisco.

[24] Roberts-Holmes, G. (2008) Doing Your Early Years Research Project. Sage Publications Ltd., London. 
[25] Bell, J. (2010) Doing Your Research Project. Open University Press, Berkshire.

[26] Stake, R.E. (1995) The Art of Case Study Research. Sage Publications, Inc., California.

[27] Riessman, C.K. (2008) Narrative Methods for the Human Sciences. Sage Publications, Inc., California.

[28] Zhou, X. (2011) Early Childhood Education Policy Development in China. International Journal of Child Care and Education Policy, 5, 29-39.

[29] Spodek, B. and Saracho, O.N. (2005) International Perspectives on Research in Early Childhood Education. Information Age Publishing, Inc., Greenwich. 
Scientific Research Publishing (SCIRP) is one of the largest Open Access journal publishers. It is currently publishing more than 200 open access, online, peer-reviewed journals covering a wide range of academic disciplines. SCIRP serves the worldwide academic communities and contributes to the progress and application of science with its publication.

Other selected journals from SCIRP are listed as below. Submit your manuscript to us via either submit@scirp.org or Online Submission Portal.
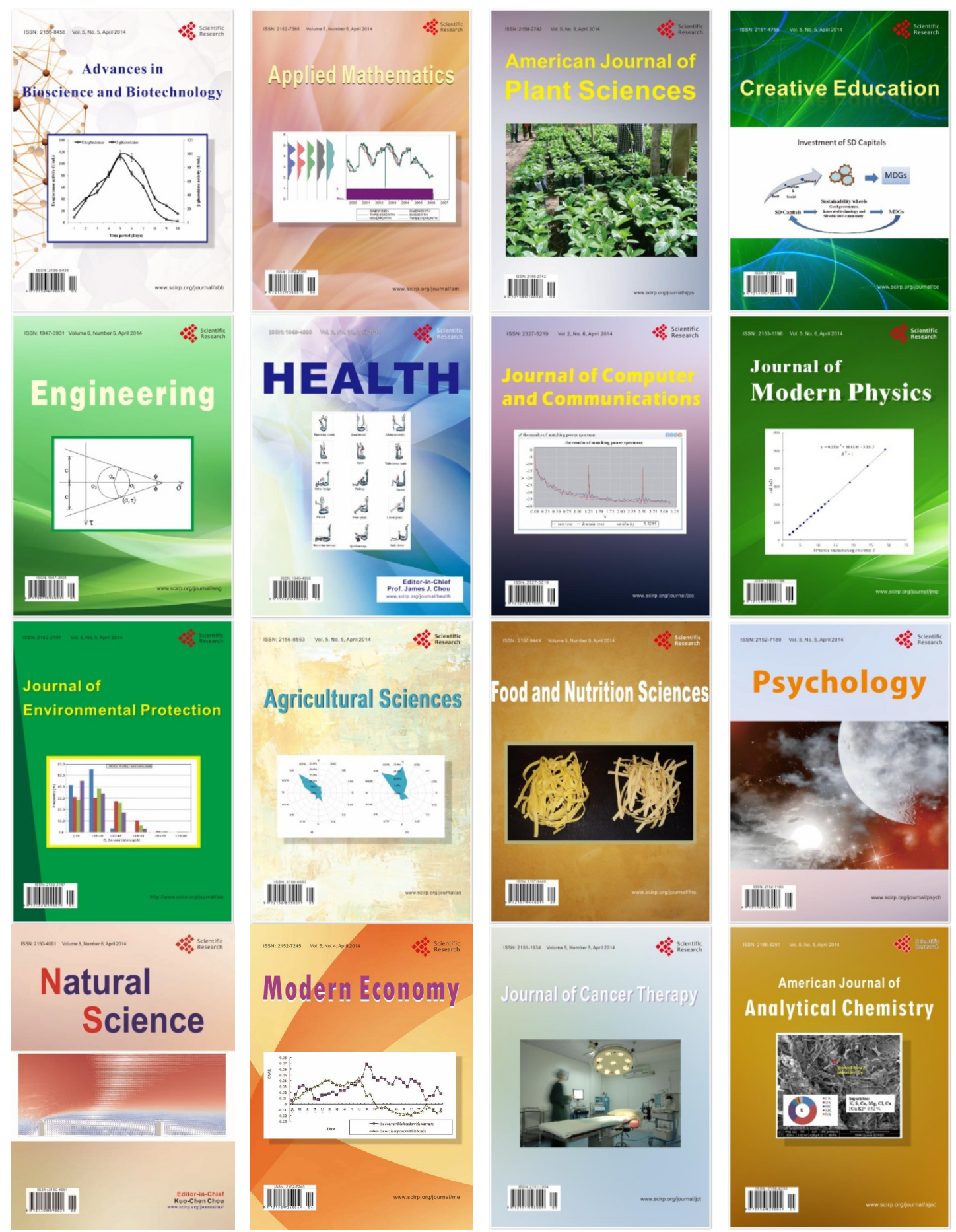